English-to the literature in English, French, German, Russian and other languages, published during the period from the first Thorium Fuel Cycle Symposium in Gatlinburg, Tennessee, held in December 1962, to the middle of 1969. The references, mainly from $\mathrm{Nu}$ clear Science Abstracts, are listed alphabetically by first author and when no personal or corporate author is given, by title. All non-English titles are translated into English, with the original language indicated in parentheses. An Introduction outlines the scope of the topics covered in compiling this bibliography. An Author Index and a Subject Index are given at the end of the bibliography. The Subject Index is in the form of a KeyWord-In-Context (KWIC) index, for which titles have been edited, where necessary, and non-significant words have been disregarded during permutation.

The Corrosion of Metals in Marine Environments, by Frederick $W$. Fink and Walter K. Boyd. Sponsored by the Defense Metals Information Center, Battelle Memorial Institute. (DMIC Report 245.)

Published in 1970 by Bayer and Company, Inc. 1380 Holly Avenue, Columbus, Ohio 43212, \$17.65; 90 pages, bound.

This book is designed to provide a comprehensive, current resource of information on the advanced metals and their utilization. Coverage includes the ocean environment: factors affecting the corrosivity of sea water and forms of corrosion; corrosion of metals in the marine environment: carbon steel, lowalloy steels, stainless steels, nickel and nickel-base alloys, cobalt, copper and copper-base alloys, titantium and titanium-base alloys, aluminum and aluminum-base alloys, beryllium, magnesium, special purpose metals-refractory metals, noble metals, and lead, zinc, cadmium, and tin-and cathodic protection. An extensive bibliography is included and an appendix gives designations and compositions of selected copper and aluminum alloys.

Advances in X-Ray Analysis, Volume 13, edited by Burton $L$. Henke et al. Proceedings of the 18th annual conference on Applications of X-Ray Analysis, held August 6-8, 1969. Sponsored by the University of Denver, Denver Research Institute, Metallurgy Division.

Published in 1970 by Plenum Press, 227 Wes 17 th Street, New York, N.Y. 10011, \$25.00; 681 pages, bound.

Emphasizing the uses of low energy $X$-rays, this conference consisted of six sessions: low energy $\mathrm{X}$-rays and $\mathrm{X}$-ray astronomy; $\mathrm{X}$-ray diffraction applications; bonding and valence effects on X-ray spectra; X-ray fluorescence applications; studies for emission spectra; and absorption and special diffraction applications. It dealt with the application of current methods to establish problem areas and with the introduction of new methods and applications, recognizing and relevance of basic physics and chemistry and the total interaction of X-rays with matter.

Notes and comments

on the injection of

\title{
auxiliary hydrocarbons
}

in the blast furnace

\section{by Kenneth C. McCutcheon, consultant}

Those interested in production of metallized iron peliets or ore in a shaft furnace for use in solid form, such as for melting stock in the electric furnace, want to produce it at as low a temperature as possible. This helps to avoid slag formation and to simplify cooling without subsequent reoxidation. Injection should be made at a reducing gas temperature of $1850-2000^{\circ} \mathrm{F}$.

The idea in blast furnace injection should be to save as much coke as possible, and to achieve the greatest production possible per lb of coke burned at the tuyere level. To achieve this economy, the reducing gas made outside the furnace by reforming auxiliary hydrocarbons should be introduced at the plastic seam at the temperature of the gases rising at that level (about $2850^{\circ} \mathrm{F}$ ). In addition to doing all the necessary reducing, the gas brings in additional heat which will be used to heat all decending materials in the charge-coke, ore, flux, metallized ore and pellets-and save coke. Otherwise, it would be necessary to charge at the top, dry, preheat in the shaft, and burn at the tuyere level. This process makes it possible to charge more ore per lb of coke, thereby increasing production and reducing coke consumption.

To furnish the additional heat required to smelt the additional metallized ore (or pellets) and the gangue material being brought down into the smelting zone by the injections, it is necessary to use as much additional blast heat as available, and beyond this to use as much oxygen through the tuyeres as is needed to keep the furnace operating properly and to make iron of the desired analysis. This is known as the Raick Double Injection Process.

Reducing gas introduced above the level of the plastic seam still leaves the necessity of heating the stock column materials descending from this level to the bottom by coke burned at the tuyere level. This coke must be charged at the top, and this limits coke saving and decreases production.

Auxiliary hydrocarbons, whether reformed outside or not, introduced below the plastic seam-even at the tuyeres-will be below the temperature of the rising gases and will limit coke saving and decrease production because coke must be burned at the tuyeres to raise the gas temperature. If the introduction of auxiliary hydrocarbons is properly done, there can be some coke saving and some increase in production. When auxiliary hydrocarbons are correctly introduced at the plastic seam there will be a possibility of a larger coke saving per ton and a greater production increase than when introduction is made at any other location. The largest injection of auxiliary hydrocarbons can be made at the plastic seam, and thus replace or save the largest amount of coke and make the largest production increase.

Tuyere level injection is standard practice. Injection at $180^{\circ} \mathrm{F}$ was made experimentally at Bruceton. The Japanese report successful injection at what seems to be the plastic seam, which is what Raick proposed in 1952, and no one but the Japanese have reported using as yet: they discussed the process several times with Dr. Raick before starting development.

Dr. Raick's process is available for use in the U.S. and elsewhere. This process makes changes in the rising gas phases at two levels, and they must be properly related. It is probable that all the experimenting and development with injection of auxiliary hydrocarbons is the result of a paper given by Dr. Raick before the Institute of American Engineers in 1952, and published in their journal The American Engineer, in which he proposed the double injection process as the best alternative to the standard blast furnace process. The double injection process will increase production in any existing furnace while saving $40-45 \%$ in coke, making it unnecessary to build more coke ovens or enlarge existing furnaces. 